\title{
Sustainability Study on Heavy Metal Uptake in Neem Biodiesel Using Selective Catalytic Preparation and Hyphenated Mass Spectrometry
}

\section{Mirella Elkadi ${ }^{1}{ }^{*}$, Avin Pillay ${ }^{1}$, Johnson Manuel ${ }^{1}$, Mohammad Zubair Khan ${ }^{1}$, Sasi Stephen ${ }^{1}$ and Arman Molki ${ }^{2}$}

1 Department of Chemistry, The Petroleum Institute, P.O. Box 2533 Abu Dhabi, UAE; E-Mails: apillay@pi.ac.ae (A.P.); jmanuel@pi.ac.ae (J.M.); mkhan@pi.ac.ae (M.Z.K.); sstephen@pi.ac.ae (S.S.)

2 Department of Mechanical Engineering, The Petroleum Institute, P.O. Box 2533 Abu Dhabi, UAE; E-Mail: amolki@pi.ac.ae

* Author to whom correspondence should be addressed; E-Mail: melkadi@pi.ac.ae; Tel.: +971-2607-5621; Fax: +971-2607-5200.

Received: 26 February 2014; in revised form: 8 April 2014 / Accepted: 9 April 2014 / Published: 25 April 2014

\begin{abstract}
It is common knowledge that the presence of trace metals in biofuels can be detrimental to the environment and long-term sustainable development. This study provides an insight into selective catalytic preparation of biofuel to compare uptake of trace metals in the biodiesel fraction with preferential base catalysts. The role of specific metal hydroxides in controlling trace metal content in biofuel production is relatively unexplored, and the effect of different homogeneous catalysts $(\mathrm{NaOH}, \mathrm{KOH})$ on metal retention in biodiesel from commercial neem oil was examined. A detailed study of this nature of catalyst $v s$. metal uptake is in the interest of sustainable living and could make a significant contribution to biofuels research. Both catalysts displayed variable uptake for certain toxic elements, which was attributed to the behavior of the catalyst in the reaction mixture. A general comparison reflected specific trends in metal retention (ICP-MS) with the use of different base catalysts. Challenges encountered by extending the study and using a heterogeneous catalyst $(\mathrm{CaO})$ are presented. Our work could play a significant role in influencing catalyzed transesterfication processes to control elemental and toxic metal uptake in biofuels. The impact of our work on sustainable living is presented.
\end{abstract}


Keywords: biodiesel; trace/toxic metals; sustainability; homogeneous/heterogeneous catalysts; ICP-MS

\section{Introduction}

Researchers in alternative energy and sustainable development [1-16] are becoming increasingly aware that a key objective in biofuel studies is to minimize the trace metal content of the biodiesel fraction. It is well known that abnormal metal content of biofuel is deleterious to the environment [17-23] as well as engines [24-28] and could spawn costly demetallization processes. It has been previously reported by the authors that trace metals and heavy elements in biodiesel play a multiple role in diminishing the performance of machinery [29]. There is a tendency for such metals to encrust fuel lines with oxide deposits and fray rubber hosing [24-29]. It would therefore be beneficial to employ a process to control the uptake of trace and toxic elements. For this purpose our study investigated the effects of different base catalysts on metal uptake in biodiesel preparation and subsequent elemental detection by high performance ICP-MS (inductively coupled plasma mass spectrometry). Over the years, ICP-MS has demonstrated its prowess [29] among contemporary analytical techniques (such as $\mathrm{X}$-ray fluorescence (XRF), inductively coupled plasma optical emission spectrometry (ICP-OES) and neutron activation for attaining superior limits of detection especially for heavy metals and toxic elements, including the lanthanides and actinides. The multi-elemental capability of this hyphenated method to determine elemental levels in the sub-ppb range (ng/L) has certainly overtaken most modern instrumental techniques.

Biodiesel has gained international recognition as an engine fuel additive. It is favored for its low toxicity, high degradability, general reduction of engine emissions and its role in sustainable development [17-26]. Reduction in $\mathrm{CO}_{2}$ emissions is more pronounced for biodiesel from vegetable oil and it has emerged that biofuel production from non-edible biomass is more economical and more compatible with regular diesel fuel [19-23]. Our biofuel was derived from neem oil using a combination of homogeneous $(\mathrm{NaOH}, \mathrm{KOH})$ and heterogeneous $(\mathrm{CaO})$ catalysts [30-32]. The comparative impact of base catalysts in controlling metal retention in the biodiesel fraction is underexplored. Both types of base catalysts have been widely employed in biofuel preparation and are associated with their own particular merits and drawbacks. Our study investigated the capability of these base catalysts in regulating trace metal uptake in the biodiesel component; and the experimental results showed that certain trends existed for transition metals and other elements with the use of different catalysts.

\section{Materials and Methods}

\subsection{Sample Treatment}

Neem oil contains steroids (campesterol, beta-sitosterol, stigmasterol) and appreciable levels of triterpenoids of which Azadirachtin is the most well-known and studied. The average composition of neem oil fatty acids [33] is: Omega-6 linoleic acid: 6\%-16\%; Omega-9 oleic acid: 25\%-54\%; 
Hexadecanoic acid: 16\%-33\%; Octadecanoic acid: 9\%-24\%. Due to the appreciable free fatty acid (FFA) content of neem oil a two-step acid/base process with commercial neem oil was used for biodiesel production [33]. Initially the commercial neem oil (of Indian origin, procured from local outlets) underwent acid-catalyzed esterification $\left(\sim 2 \%\right.$ wt $\left.\mathrm{H}_{2} \mathrm{SO}_{4}\right)$ in methanol, followed by (homogeneous) base-catalyzed $(\mathrm{NaOH}, \mathrm{KOH})$ conversion (< $1 \%$ wt catalyst) with methanol (methanol/oil ratio 1:4 v/v) under suitable thermal and reaction conditions. The chemical basis of vegetable oils, regardless of their origins, is triglyceride, which consists of glycerol and three carboxylic or fatty acids [1,33]. Biodiesel, in general, and from neem oil in particular, involves conversion of these long and branched chain triglyceride molecules to its methyl esters. These esters display similar fuel properties to those of petroleum diesel and the glycerol, a significant by-product of this chemical reaction, is removed by suitable separation and purification processes [29,33]. A single step process using direct alkaline treatment was avoided due to the significant FFA levels. The dual acid/base treatment was thus necessary for satisfactory conversion of the FFA to mono-esters. The first step was essentially a pre-treatment process that reduced the fatty acids in the oil. The next and final stage was the alkaline transesterification step that converted the products to biodiesel and glycerol. The glycerol is not an entirely undesirable product as it can be recovered and refined and has its uses in other industrial and chemical processes. The drawback with homogeneous catalysts is that they cannot be recovered and reused. Subsequently, the potential of $\mathrm{CaO}$ (anhydrous) as heterogeneous catalyst was investigated as a bed of solid granules in the reaction mixture (during transesterification) with methanol under reflux conditions. Samples were prepared in aqueous media prior to ICP-MS analysis. Standard fuel properties were measured, as previously reported by the authors [29].

\subsection{High-Resolution ICP-MS}

Biodiesel samples (in dilute aqueous solution) were submitted to elemental analysis using a Perkin Elmer SCIEX DRC-e ICP-MS (Figure 1).

Figure 1. A schematic of the inductively coupled plasma mass spectrometry (ICP-MS) instrument.

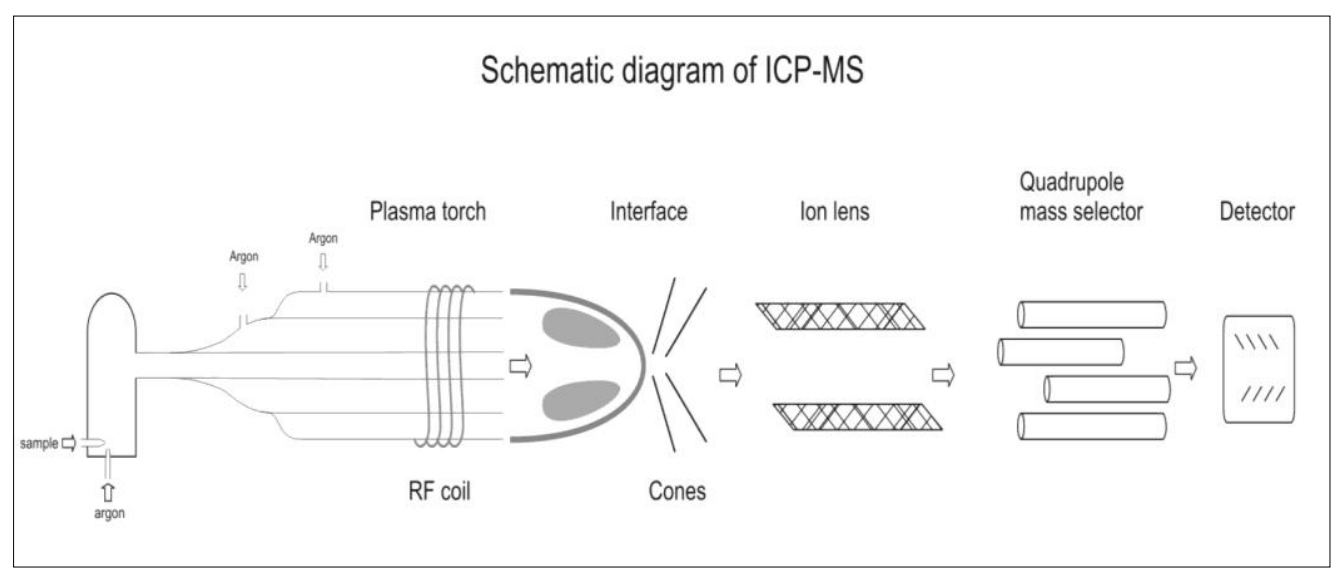

The solution containing the biodiesel was finely nebulized and transported to a high-temperature plasma ( $\sim 6000 \mathrm{~K})$ where it was atomized and transformed to ions (characteristic of the elements of the sample), which were subsequently transported to a mass spectrometer for detection. For optimal performance the instrumental argon gas flow was $0.80 \mathrm{~L} / \mathrm{min}$. The technique is ultra-sensitive [34] and 
can attain lower limits of detection in the $\mathrm{ng} / \mathrm{L}$ range (sub-ppb) for most elements. Small quantities $(200 \mu \mathrm{L})$ of the neem biodiesel samples (produced in our laboratory) were digested in strong acidic media $\left(\mathrm{HNO}_{3} / \mathrm{HF}, 4: 1 \mathrm{v} / \mathrm{v}\right)$ using an industrial grade microwave oven. All samples were treated under identical conditions. The digested samples were further diluted and then analyzed using the high-performance ICP-MS instrument. The technique was standardized with suitable reference standards. A suitable internal standard was used to compensate for possible drift in instrument measurements.

\subsection{Instrumental Performance}

Spectra were generated to observe variations in characteristic metal intensity with catalyst. Careful consideration was given to the impact of interferences and matrix effects. Prior to each run, the instrument underwent appropriate calibration and correction for background. An aqueous certified standard (Fluka 70007; $10.0 \mathrm{ppb}$ per element) was available to test the performance of the instrument on homogeneous aqueous solutions. Of significance is that the instrument was programmed to aspirate three aliquots of sample in quick succession and recorded the mean and deviation from the mean. These are instrumental relative standard deviation (RSD) values, and appear in Table 1. Corresponding error bars appear in Figures in Section 3, and are not indicative of sample preparation errors. Repeatability data (Table 1) show that in general, relative standard deviations of less than $5 \%$ were attained demonstrating that the performance of the system for aqueous samples was satisfactory.

Table 1. Repeatability study (ppb) using a multielemental aqueous standard (Fluka 70007).

\begin{tabular}{cccccccc}
\hline Measurement & Be & Mg & Co & Ni & In & Ce & Bi \\
\hline 1 & 10.5 & 10.3 & 9.9 & 9.9 & 9.6 & 9.8 & 9.1 \\
2 & 10.7 & 10.6 & 10.6 & 10.1 & 9.5 & 9.1 & 9.6 \\
3 & 10.6 & 10.6 & 9.9 & 10 & 9.6 & 9.2 & 9.1 \\
Mean \pm RSD & $10.6 \pm 0.94 \%$ & $10.5 \pm 1.7 \%$ & $10.1 \pm 4.0 \%$ & $10.0 \pm 1.0 \%$ & $9.6 \pm 0.6 \%$ & $9.4 \pm 4.0 \%$ & $9.3 \pm 3.1 \%$ \\
\hline
\end{tabular}

\section{Results and Discussion}

\subsection{Homogeneous and Heterogeneous Base Catalysts}

\subsubsection{Homogeneous Catalysts}

The process of reducing FFA in commercial neem oil to satisfactory levels before carrying out a successful transesterification to produce biodiesel is still underexplored. The free fatty acid content in neem oil is relatively high and leads to undesirable effects such as soap formation and incomplete conversion [29,33]. From our laboratory trials it was observed that an appreciable alcohol to oil ratio is required for converting FFAs to methyl esters. The problem though, is that if the experimental conditions are imperfect, use of these catalysts could result in reduced yields. Therefore, to eliminate unwanted products and improve the biodiesel yield and quality it was necessary to adhere closely to reaction conditions. Although the two-step acid/base process is necessary for optimal yields it is tedious and time-consuming and could result in slight loss of valuable oil when proceeding from one step to the next. As expected, homogeneous catalysts, $\mathrm{NaOH}$ and $\mathrm{KOH}$, were particularly reactive leading to biofuel conversion (yields: $\sim 60 \%$ for $\mathrm{NaOH}$; $~ 65 \%$ for $\mathrm{KOH}$ ) in about $1-2 \mathrm{~h}$ under 
constant stirring and relatively mild thermal conditions $\left(45-60{ }^{\circ} \mathrm{C}\right)$. A slightly higher yield was achieved with $\mathrm{KOH}$ and this could be attributed to the higher reactivity of the methoxide anion (formed from the reaction between hydroxide with methanol) in the presence of $\mathrm{K}^{+}$than $\mathrm{Na}^{+}$due to the stronger affinity of the latter (smaller) cation for methoxide [35]. The methoxide anion in the reaction mixture acts as a powerful Lewis base and is more readily available to react with the acyl groups in the triglycerides because it displays weaker attraction in the case of potassium than sodium. A common drawback in the use of these base catalysts is constant washing for their removal and separation of the products. The fuel properties of the biodiesel from homogeneous base catalyst were reported previously by the authors [29] and are not repeated here.

\subsubsection{Heterogeneous Catalyst}

The use of $\mathrm{CaO}$ presented several unanticipated difficulties. To establish reaction parameters a preliminary study was conducted (under identical conditions) employing $\mathrm{CaO}$ as a homogeneous catalyst by converting to methoxide in methanol and filtering the residual solid. This was not particularly successful and obviously led to diminished stoichiometric level of the catalyst resulting in an incomplete reaction and a turbid biodiesel fraction. An extension to this procedure with $\mathrm{CaO}$ in heterogeneous form as a bed of solid granules in the reaction mixture generated products that were difficult to separate. This was unexpected and attributed to the complex nature of the conversion and the chemical properties of the neem oil itself. In theory, the transesterification process is an equilibrium reaction and it is surmised that in the presence of solid $\mathrm{CaO}$ the shift in equilibrium towards formation of products is not favoured thus suppressing the in situ methoxide anion from reacting freely [31,32]. A significant factor considered to hinder the forward-shift in equilibrium is the strong association of the doubly charged $\mathrm{Ca}^{2+}$ cation with methoxide [13], which makes it even less available for reaction than in the cases of $\mathrm{KOH}$ and $\mathrm{NaOH}$. For future study, one possibility of improving the yield and quality of the biodiesel with $\mathrm{CaO}$ is to consider addition of small quantities of crown ether [13] to the reaction mixture to free the in situ methoxide for more active participation in the conversion process.

\subsection{Selectivity of Metal Uptake}

Definite trends in metal uptake were observed. The source of these elements was the neem oil itself. Analysis of the oil (not shown) revealed a wide range of elements whose origins lie in the neem plant and technological processes related to production of the oil. It was stated in our previous paper [29] that growth conditions - such as soil, water and cultivation methods - play an important role in the quality of the biodiesel. We found that biodiesel produced from $\mathrm{NaOH}$ showed a distinct predilection for retention of some common transition metals, while that from $\mathrm{KOH}$ displayed a consistent uptake for the lighter elements. Both catalysts showed mixed uptake for other heavier elements. Selectivity of this nature was unexpected (and significant in some cases) and is discussed in detail below.

\subsubsection{Light Elements $(Z \leq 20)$}

Figure 2 represents a plot of metal concentration in biodiesel generated from $\mathrm{NaOH}$ and $\mathrm{KOH}$ for some light elements. It is clear that the process with $\mathrm{NaOH}$ led to a systematic lower metal uptake in 
the biodiesel product. In some cases, such as $\mathrm{Li}$, the levels differed by more than a factor of $2(\sim 70$ and $\sim 180 \mathrm{ppb}$ for $\mathrm{NaOH}$ and $\mathrm{KOH}$, respectively). This sharp difference is not clear and could be due to greater affinity of the smaller $\mathrm{Li}^{+}$ion for the glycerol fraction in the presence of the less competitive and unwieldy $\mathrm{K}^{+}$cation [35]. The Be levels displayed the same consistency (lower levels with $\mathrm{NaOH}$ ) but were unusually elevated ( 150 and $\sim 160 \mathrm{ppb}$ ) compared to data in our previous report on biofuel abstracted directly from neem fruit and kernels [29]. The Al and P concentrations delineated a similar trend reflecting slightly depressed levels with $\mathrm{NaOH}$ conversion $(\sim 60$ and $\sim 80$ ppm for $\mathrm{Al} ; \sim 190$ and $\sim 210 \mathrm{ppm}$ for $\mathrm{P}$ ). These levels for $\mathrm{Al}$ and $\mathrm{P}$ were also considered to be comparatively elevated. Similarly, $\mathrm{Mg}$ and $\mathrm{Ca}$ were somewhat diminished in connection with $\mathrm{NaOH}$ preparation. This systematic occurrence of consistently lower levels with $\mathrm{NaOH}$ treatment was unusual, and it was surmised that these particular elements had weaker affinity for the glycerol fraction in the presence of concentrated and competitive $\mathrm{Na}^{+}$cations (from the catalyst) and were thus displaced into the biodiesel component [13]. The presence of comparable levels of $\mathrm{Na}$ in Figure 2 is an indicator that the catalyst is not a source of impurities (as expected).

Figure 2. Concentrations of representative elements in biodiesel showing systematic uptake with $\mathrm{KOH}$ treatment.

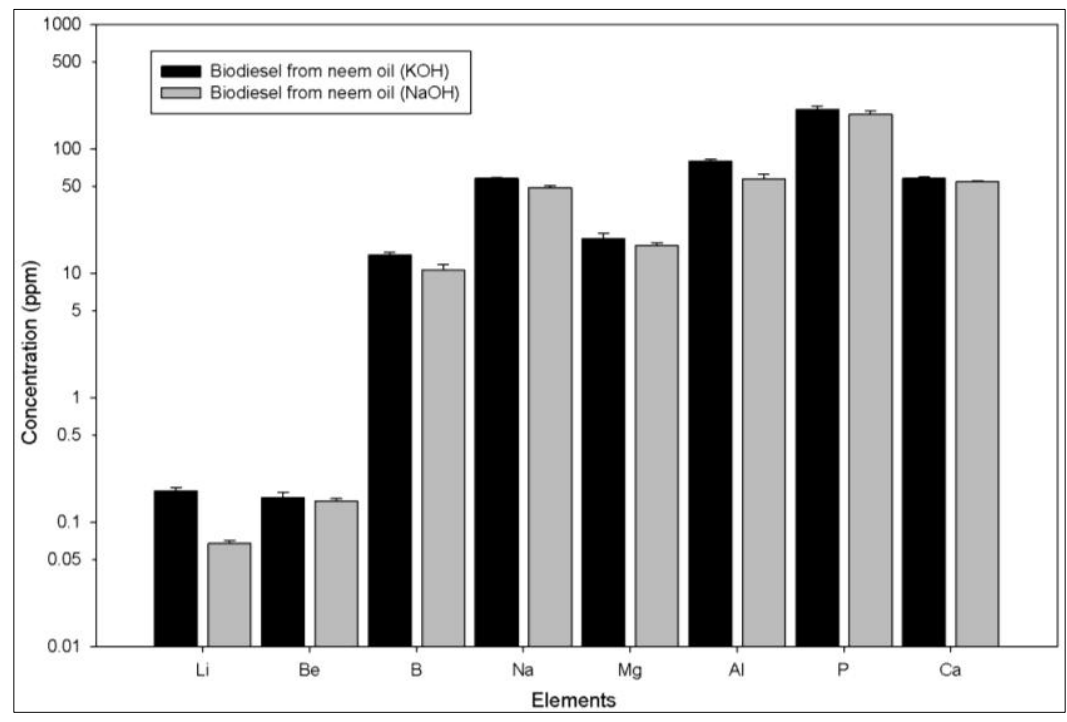

\subsubsection{First-Row Transition Metals}

A broken trend was observed for the transition metals (Figure 3). Treatment with $\mathrm{KOH}$ resulted in lower uptake in the biodiesel for some metals ( $\mathrm{Ti}, \mathrm{Cr}, \mathrm{Mn}, \mathrm{Ni}$ ) compared to the $\mathrm{NaOH}$ conversion. These particular transition metals display higher multiple oxidation states ( $\mathrm{Mn}$, for example, has five oxidation states), and probably have a stronger potential to form complex ions in the reaction mixture. This suggests a more vigorous competition for the formation of polydentate complexes with the glycerol fraction in the presence of the bulkier and less competitive $\mathrm{K}^{+}$cation [35]. Thus, these specific transition metals were relatively depleted in the biodiesel component with $\mathrm{KOH}$ treatment. In some cases pronounced differences in levels were found for certain elements. Titanium displayed comparatively higher concentrations than the others $(\sim 190$ and $\sim 210$ ppm for $\mathrm{KOH}$ and $\mathrm{NaOH}$, respectively) indicating the neem oil itself possibly originated from titanium rich soil; or the process in 
producing the oil led to Ti contamination. Here again we see how important growth conditions are in transporting such metal impurities from the plant itself to the vegetable oil.

Figure 3. Concentrations of the transition metals in biodiesel showing specific uptake with $\mathrm{KOH}$ and $\mathrm{NaOH}$.

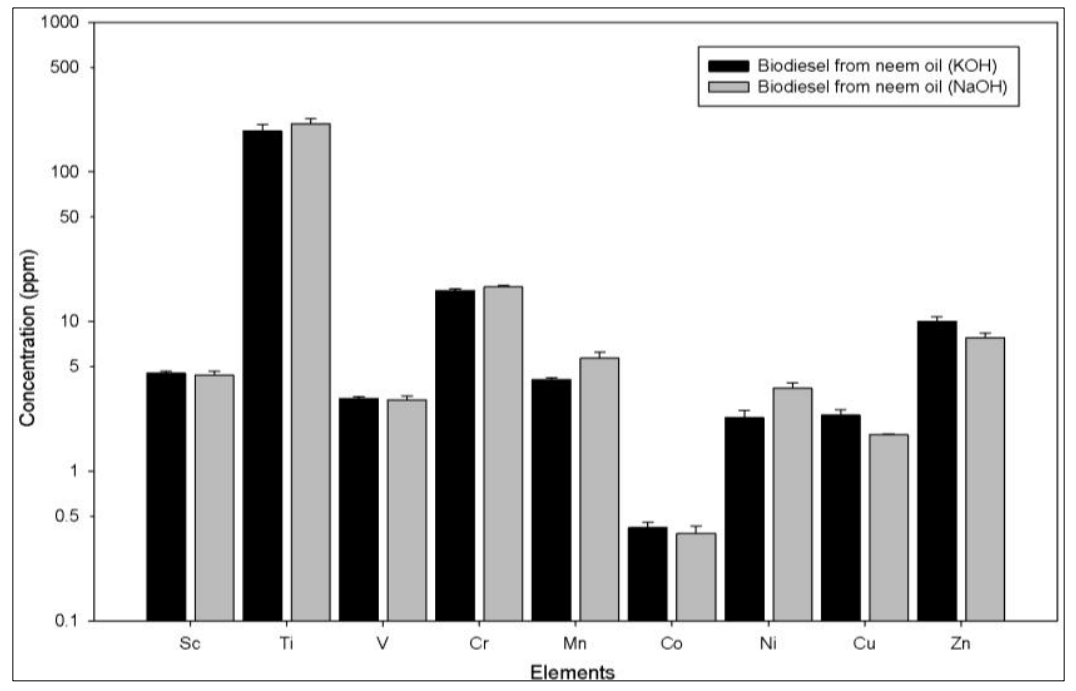

\subsubsection{Heavy Elements $(Z>30)$}

There was no clear-cut trend in this case (Figures 4 and 5), and no dramatic differences were recorded with the exception of tungsten (W) whose concentrations differed by more than a factor of five ( 1600 and $\sim 300 \mathrm{ppb}$ for $\mathrm{NaOH}$ and $\mathrm{KOH}$, respectively). Tungsten is an "exotic" element, not particularly prolific, so this unusually high difference is not clear [29]. The lanthanides - La ( 30, $\sim 20 \mathrm{ppb})$ and $\mathrm{Ce}(\sim 60 \mathrm{ppb}$ for both treatments) - were present at levels that could possibly be expected. However, it is interesting to find that the actinides-Th $(\sim 30, \sim 28 \mathrm{ppb})$ and $\mathrm{U}(\sim 7$, $\sim 4 \mathrm{ppb}$ ) — were present at appreciable levels. Some plants tend to be good indicators of metals present in the soil and it is possible that the neem tree is a "reflector" of Th and U levels in the ground.

Figure 4. Concentrations of elements $33<\mathrm{Z}<51$ in biodiesel after treatment with $\mathrm{KOH}$ and $\mathrm{NaOH}$.

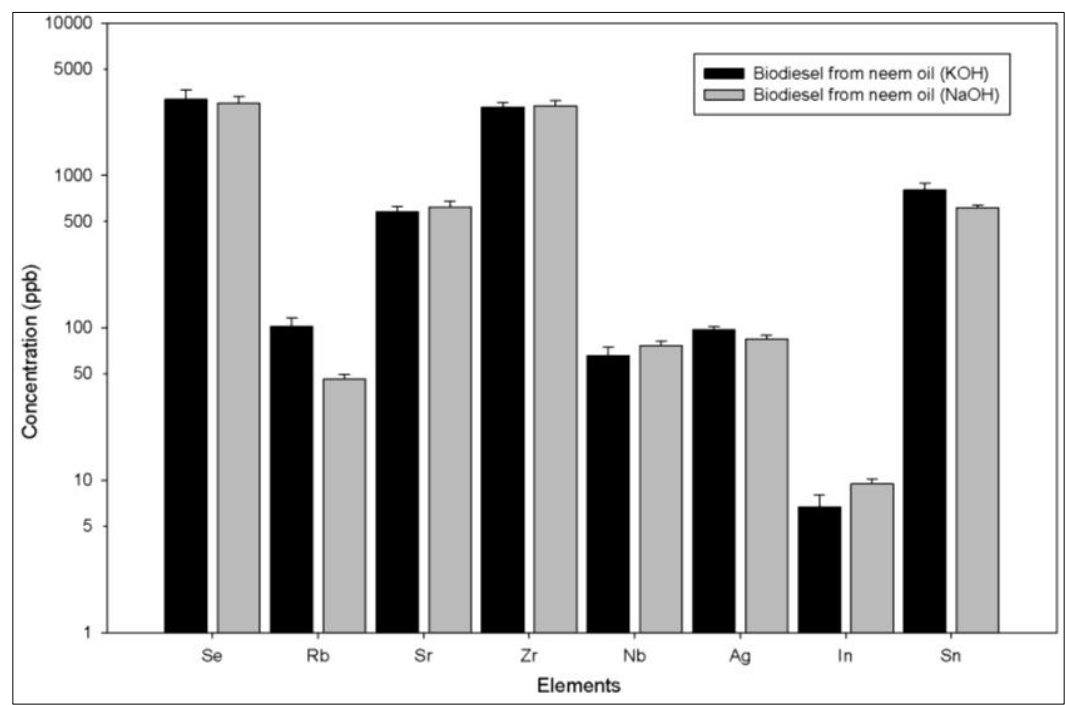




\subsection{Sustainability/Environmental Implications}

The study has a direct impact on the environment because it can be linked to sustainable living [36,37]. Pollution from biodiesel has not been given much attention because it has not (as yet) reached the level of recognition (and application) as petro-diesel. However, toxic metals from biodiesel can find its way into the environment by various means. Lower levels of some toxic elements (Be, Se, $\mathrm{Tl}, \mathrm{Pb}, \mathrm{Bi}$ ) were produced by treatment with $\mathrm{NaOH}$ (Figures 2, 4 and 5). On the other hand, lower measured concentrations of other toxic elements ( $\mathrm{Sb}, \mathrm{Th}$ ) were recorded with $\mathrm{KOH}$ treatment (Figure 5). These deleterious elements can be released into the atmosphere as exhaust fumes from biodiesel combustion [20,29] and could also migrate into the soil and water table, especially if poor quality biofuel is dumped. Sustainable development is the key factor in producing biofuel and it is necessary to guard against the threat of contamination. The admissible levels of most toxic elements in air and water are in the low $\mu \mathrm{g} / \mathrm{L}$ range [38] and in view of this it is clear from Figures 2, 4 and 5 that the levels of the aforementioned elements $(\mathrm{Be}, \mathrm{Se}, \mathrm{Sb}, \mathrm{Tl}, \mathrm{Pb}, \mathrm{Bi}, \mathrm{Th}$ ) from both processes are elevated. Here again, base catalyst influences selective elemental uptake, and as global production of biofuel increases, the unpleasant prospect of environmental pollution will naturally increase, unless the catalytic treatment is refined. Attempting to mitigate climate change on the one hand and contaminating the environment on the other is not sensible and suitable procedures should be adopted to generate low toxicity biofuel. Undoubtedly, yield $v s$. trace metal toxicity is an essential consideration in biofuel production and choice of base catalyst will certainly play a major role. From our study it is difficult to say which base catalyst is favored but it seems from the results that despite lower yields and, in the interest of sustainable development, treatment with $\mathrm{NaOH}$ tends to have greater efficacy. If yields could be improved this particular base catalyst should be employed.

Figure 5. Concentrations of elements $50<\mathrm{Z}<93$ in biodiesel after treatment with $\mathrm{KOH}$ and $\mathrm{NaOH}$.

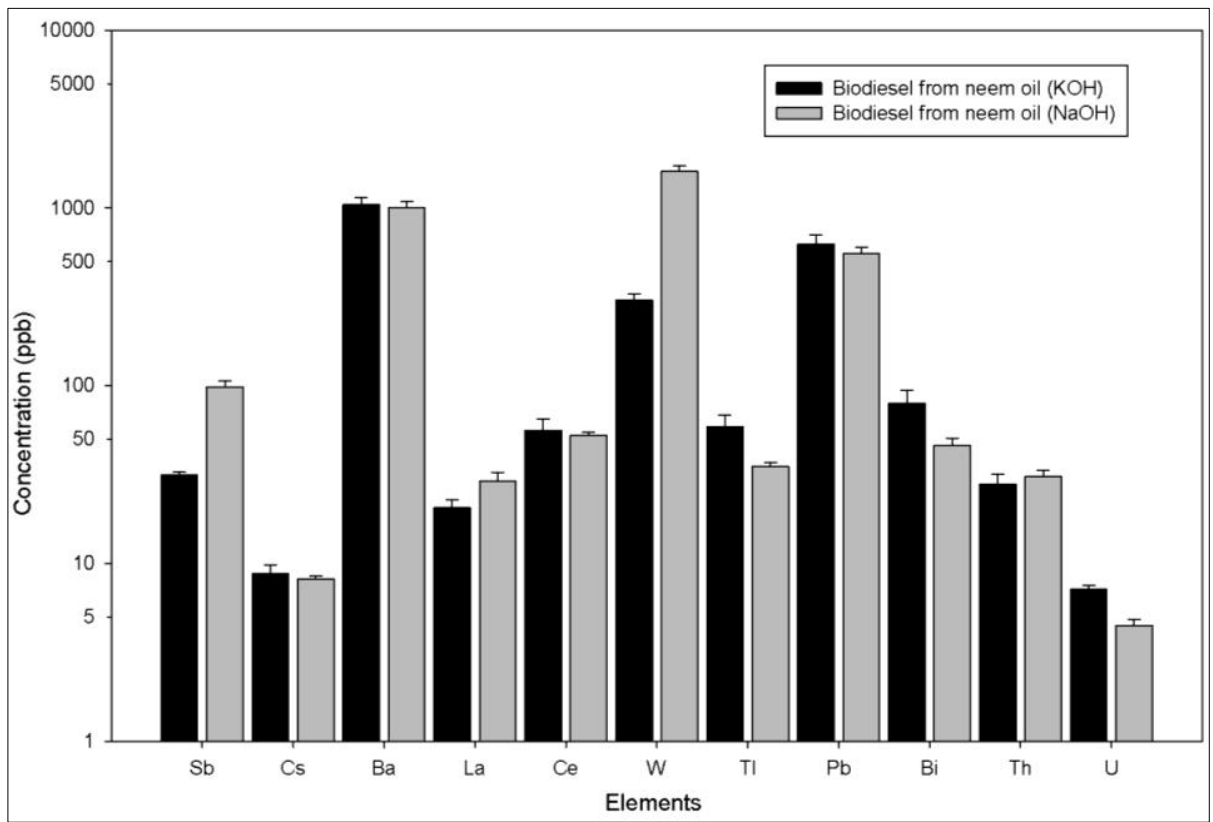




\section{Conclusions}

We have found that selective metal uptake in biodiesel exists with different base catalysts. The influence of homogeneous catalysts $(\mathrm{NaOH}, \mathrm{KOH})$ on metal retention in biodiesel from neem oil led to distinct trends in uptake of transition metals, toxic and representative elements. This was attributed to the unique behavior of the catalyst and specific chemical properties of neem biodiesel. It is well known that such metals and toxic elements affect the performance of machinery and are unfriendly to the environment, therefore, appropriate measures should be taken to minimize their presence in biodiesel. For example, the feasibility of reducing elemental uptake in the biodiesel fraction by introducing an appropriate chelating additive could be the subject of further research. And to improve yields with both homogeneous and heterogeneous catalysts, combined use of small amounts of crown ethers to make the methoxide more available for reaction is a factor to be considered in an extended study. Selective uptake of certain toxic elements emphasizes that the choice of base catalyst in biofuel production cannot be understated, and to preserve sustainable living suitable catalytic treatment should be adopted.

\section{Acknowledgements}

The authors wish to thank the Petroleum Institute for financial support.

\section{Author Contributions}

Mirella Elkadi supervised the catalytic preparation of neem biodiesel. Avin Pillay supervised the instrumental analysis. Johnson Manuel, Mohammad Zubair and Arman Molki were involved in preparation and characterization of the biofuel. Sasi Stephen was responsible for operating the ICP-MS and producing the analytical data.

\section{Conflicts of Interest}

The authors declare no conflict of interest.

\section{References}

1. Ma, F.; Hanna, M.A. Biodiesel production: A review. Bioresour. Technol. 1999, 70, 1-15.

2. Achten, W.M.J.; Mathijs, E.; Verchot, L.; Singh, V.P.; Aerts, R.; Muys, B. Jatropha biodiesel fueling sustainability a perspective. Biofuels. Bioprod. Biorefin. 2007, 1, 283-291.

3. Becker, K.; Makkar, H.P.S. Jatropha curcas: A potential source for tomorrow's oil and biodiesel. Lipid Technol. 2008, 20, 104-107.

4. Makkar, H.P.S.; Becker, K. Jatropha curcas: A promising crop for the generation of biodiesel and value-added coproducts. Eur. J. Lipid Sci. Technol. 2009, 111, 773-787.

5. Helwani, Z.; Othman, M.R.; Aziz, N.; Kim, J.; Fernando, W.J.N. Solid catalysis for transesterification of triglycerides with methanol. Appl. Catal. A 2009, 363, 1-10.

6. Leung, D.Y.C.; Wu, X.; Leung, M.K.H. A review on biodiesel production using catalyzed transesterification. Appl. Energy 2010, 87, 1083-1095. 
7. Lee, D.W.; Park, Y.M.; Lee, K.Y. Heterogeneous base catalysts for transesterification in biodiesel synthesis. Catal. Surv. Asia 2009, 13, 63-77.

8. Lotero, E.; Liu, Y.; Lopez, D.E.; Suwannakarn, K.; Bruce, D.A.; Goodwin, J.G. Synthesis of biodiesel via acid catalysis. Ind. Eng. Chem. Res. 2005, 44, 5353-5363.

9. Fukuda, H.; Kondo, A.; Noda, H. Biodiesel fuel production by transesterification of oils. J. Biosci. Bioeng. 2001, 92, 405-416.

10. Berchmans, H.J.; Hirata, S. Biodiesel production from crude Jatropha curcas L. seed oil with a high content of free fatty acids. Bioresour. Technol. 2008, 99, 1716-1721.

11. Di Serio, M.; Cozzolino, M.; Giordano, M.; Tesser, R.; Patrono, P.; Santacesaria, E. From homogeneous to heterogeneous catalysts in biodiesel production. Ind. Eng. Chem. Res. 2007, 46, 6379-6384.

12. Schuchardta, U.; Serchelia, R.; Vargas, R.M. Transesterification of vegetable oils: A review. J. Braz. Chem. Soc. 1998, 9, 199-210.

13. Sivasamy, A.; Cheah, K.Y.; Fornasiero, P.; Kemausour, F.; Zinoviev, S.; Miertus, S. Catalytic applications in the production from vegetable oil. Chem. Sus. Chem. 2009, 2, 1091-1096.

14. Chhetri, A.B.; Tango, M.S.; Budge, S.M.; Watts, K.C.; Islam, M.R. Non-edible plant oils as new sources for biodiesel production. Int. J. Mol. Sci. 2008, 9, 169-180.

15. Di Serio, M.; Tesser, R.; Pengmei, L.; Santacesaria, E. Heterogeneous catalysts for biodiesel production. Energ. Fuel. 2008, 22, 207-217.

16. Demirbas, A. Comparison of transesterification methods for production of biodiesel from vegetable oils and fats. Energ. Convers. Manag. 2008, 49, 125-130.

17. Ozsezen, A.N.; Canakci, M. Determination of performance and combustion characteristics of a diesel engine fueled with canola and waste palm oil methyl esters. Energ. Convers. Manag. 2011, 52, 108-116.

18. Buyukkaya, E. Effects of biodiesel on a DI diesel engine performance, emission and combustion characteristics. Fuel 2010, 89, 3099-3105.

19. Aydin, H.; Bayindir, H. Performance and emission analysis of cottonseed oil methyl ester in a diesel engine. Renew. Energ. 2010, 35, 588-592.

20. Celikten, I.; Koca, A.; Arslan, M.A. Comparison of performance and emissions of diesel fuel, rapeseed and soybean oil methyl esters injected at different pressures. Renew. Energ. 2010, 35, 814-820.

21. Wu, F.; Wang, J.; Chen, W.; Shuai, S. A study on the emission performance of a diesel engine fueled with five typical methyl ester biodiesels. Atmos. Environ. 2009, 43, 1481-1485.

22. Lin, C.Y.; Li, R.J. Engine performance and emission characteristics of marine fish-oil biodiesel produced from the discarded parts of marine fish. Fuel Process. Tech. 2009, 90, 883-888.

23. Qi, D.H.; Geng, L.M.; Chen, H.; Bian, Y.Z.; Liu, J.; Ren, X.C. Combustion and performance evaluation of a diesel engine fueled with biodiesel produced from soybean crude oil. Renew. Energ. 2009, 34, 2706-2713.

24. Lin, B.F.; Huang, J.H.; Huang, D.Y. Experimental study of the effects of vegetable oil methyl ester on DI diesel engine performance characteristics and pollutant emissions. Fuel 2009, 88, $1779-1785$. 
25. Raheman, H.; Ghadge, S.V. Performance of compression ignition engine with mahua (Madhuca indica) biodiesel. Fuel 2007, 86, 2568-2573.

26. Rakopoulos, C.D.; Antonopoulos, K.A.; Rakopoulos, D.C.; Hountalas, D.T.; Giakoumis, E.G. Comparative performance and emissions study of a direct injection diesel engine using blends of diesel fuel with vegetable oils or bio-diesels of various origins. Energ. Convers. Manag. 2006, 47, 3272-3287.

27. Usta, N. An experimental study on performance and exhaust emissions of a diesel engine fuelled with tobacco seed oil methyl ester. Energ. Convers. Manag. 2005, 46, 2373-2386.

28. Ilkilic, C.; Yucesu, H.S. Investigation of the effect of sunflower oil methyl ester on the performance of a diesel engine. Energy Sourc. 2005, 27, 1225-1234.

29. Pillay, A.E.; Elkadi, M.; Fok, S.C.; Stephen, S.; Manuel, J.; Khan, M.Z.; Unnithan, S. A comparison of trace metal profiles of neem biodiesel and commercial biofuels using high performance ICP-MS. Fuel 2012, 97, 385-389.

30. Serio, M.D.; Ledda, M.; Cozzolino, M.; Minutillo, G.; Tesser, R.; Santacesaria, E. Transesterification of soybean oil to biodiesel by using heterogeneous basic catalysts. Ind. Eng. Chem. Res. 2006, 45, 3009-3014.

31. Liu, X.J.; He, H.Y.; Wang, Y.J.; Zhu, S.L.; Piao, X.L. Transesterification of soybean oil to biodiesel using $\mathrm{CaO}$ as a solid base catalyst. Fuel 2008, 87, 216-221.

32. Liu, X.J.; Piao, X.L.; Wang, Y.J.; Zhu, S.L.; He, H.Y. Calcium methoxide as a solid base catalyst for the transesterification of soybean oil to biodiesel with methanol. Fuel 2008, 87, 1076-1082.

33. Sekhar, M.C.; Mamilla, V.R.; Mallikarjun, M.V.; Reddy, K.V. Production of Biodiesel from Neem Oil. Int. J. Eng. Stud. 2009, 1, 295-302.

34. Jenner, G.A.; Longerich, H.P.; Jackson, S.E.; Fryer, B.J. ICP-MS-A powerful tool for high-precision trace-element analysis in Earth sciences: Evidence from analysis of selected U.S.G.S. reference samples. Chem. Geol. 1990, 83, 133-148.

35. Srokol, Z.W.; Rothenberg, G. Practical issues in catalytic and hydrothermal biomass conversion: Concentration effects on reaction pathways. Top. Catal. 2010, 53, 1258-1263.

36. Robinson, J.G. The limits to caring: sustainable living and the loss to biodiversity. Conserv. Biol. 1993, 7, 20-28.

37. Shearman, R. The meaning and ethics of sustainability. Environ. Manag. 1990, 14, 1-8.

38. De, A. Environmental Chemistry, 3rd ed; Wiley Eastern Limited: New Delhi, India, 1994.

(C) 2014 by the authors; licensee MDPI, Basel, Switzerland. This article is an open access article distributed under the terms and conditions of the Creative Commons Attribution license (http://creativecommons.org/licenses/by/3.0/) 